Proceedings of SALT 30: 801-820, 2020

\title{
Embedded presents and the structure of narratives*
}

\author{
Pranav Anand \\ University of California, Santa Cruz \\ Maziar Toosarvandani \\ University of California, Santa Cruz
}

\begin{abstract}
The orthodox view of tense mandates that the present tense, when embedded under a past attitude predicate, should give rise soley to what is called a “double access" reading (Abusch 1997; Ogihara 1996; Ogihara \& Sharvit 2012). We consider a class of embedded presents which locate the embedded eventuality neither at the time of utterance nor the time of the attitude. Unlike some other recently identified cases of ill-behaved embedded tenses, we argue that our embedded presents are instances of the historical present, a non-indexical use of the simple present. This assimilation requires abandoning current theories of the historical present, which treat it as a purely pragmatic contextual shift (Schlenker 2004; Anand \& Toosarvandani 2017). Building on Lewis (1978), we introduce an intensional operator sensitive to a salient narrative in the context, which shifts a contextual time coordinate to a temporal vantage point on that narrative. This unifies our cases of embedded presents with their matrix counterparts, in fiction and non-fiction narratives alike.
\end{abstract}

Keywords: present tense, embedded tense, indexicality, narrative, fiction

\section{Introduction}

The behavior of tenses under attitude predicates has been a principal focus of the semantics of tense. The orthodox view of the present tense in English is illustrated in the logical forms below (Abusch 1997; Ogihara 1996; Ogihara \& Sharvit 2012).

$$
\begin{array}{lr}
\operatorname{TNS}_{1} \ldots \text { АTT }\left[\operatorname{PRES}_{2} \ldots \mathrm{P}\right] & \\
\text { a. } \operatorname{PRES}_{1} \ldots \operatorname{ATT}^{e_{1}}\left[\varnothing_{2} \ldots \mathrm{P}^{e_{2}}\right] & \tau\left(e_{2}\right) \subseteq \operatorname{TiME}(u) \\
\text { b. } \operatorname{PAST}_{1} \ldots \operatorname{ATT}^{e_{1}}\left[\operatorname{PRES}_{2} \ldots \mathrm{P}^{e_{2}}\right] & \tau\left(e_{2}\right) \supseteq\left[\tau\left(e_{1}\right), \operatorname{Time}(u)\right]
\end{array}
$$

In general, PRES is indexical, picking out the time of utterance, TIME $(u)$. When the attitude predicate (ATT) and embedded predicate (P) both bear present tense, as in (1a) and (2), the mechanisms responsible for sequence of tense conspire to make the embedded present a "null tense" simultaneous with the attitude time. Consequently, the run-time of $\mathrm{P}$ is indirectly indexical, contained in the utterance time.

* We thank participants of SALT 30, particularly Catherine Anderson, Craige Roberts, and Roger Schwarzschild, for comments, as well as Kelsey Sasaki for discussion.

(C2020 Anand and Toosarvandani 
My dad thinks masks don't prevent the spread of COVID-19.

When present is embedded under past and sequence of tense does not occur, as in (1b) and (3), the embedded present tense directly requires overlap with the utterance time. Other factors imposed by the attitude (such as Abusch's (1997)'s Upper Limit Constraint) then lead to the so-called "double access" reading, in which P is located at an interval containing both the utterance time and the time of the attitude.

In March, the World Health Organization said that masks don't need to be worn by healthy people, unless they are caring for someone who is ill. ${ }^{1}$

Thus, regardless of the embedding tense, embedded presents pick out, either directly or indirectly, intervals overlapping the utterance time $(\operatorname{TIME}(u))$. In that light, the following example from a 1963 New York state trial (Willie Clark v. New York Transit Authority) is quite unexpected:

Q: How fast were you travelling when the front of your car went across the intersection and you saw the bus stop, how fast were you going?

A: Then I was doing about 15 miles an hour...

Q: And you said ${ }^{e_{1}}$ at that point you are moving ${ }^{e_{2}} \mathbf{1 5}$ miles an hour...is that right?

$\tau\left(e_{2}\right)<\tau\left(e_{1}\right)<\operatorname{TIME}(u)$

A: Yes.

In the final question, the defense attorney asks the plaintiff Willie Clark, who is on the stand in 1963, about a statement he just made regarding his actions while driving around 1:30 am on September 15, 1957. Thus, the time of the driving, $\tau\left(e_{2}\right)$, precedes the time of the statement, $\tau\left(e_{1}\right)$, which itself precedes the time of the question. And yet, the question is an instance of present-under-past (1b), which should only permit a double access reading.

Such cases, where an embedded present describes an eventuality located prior to the utterance time, are not rare and are attested across a range of genres, including the example in (5a). Nor are they particularly difficult to construct, as (5b) shows.

a. He gets maps from friends and calls in at local offices of the American Automobile Association to get directions, but still gets lost several times... I can't remember how long it takes him, but it's weeks. ${ }^{2}$

b. Warren's position on her career has changed. In a 2007 interview, she said that she leaves work to raise her family that year. On the campaign, she said that she is shown the door.

1 https://www.politico.eu/article/as-europe-masks-up-coronavirus-covid19-the-netherlands-dithers/ (accessed September 20, 2020).

2 www.antipope.org/charlie/blog-static/2006/07/travelling.html (accessed September 20, 2020). 
Our central intuition is that these embedded presents are instances of the historical present $(H P)$, which is sometimes also called the "narrative" present. The HP appears in root contexts, describing actual eventualities located in the past of the utterance time, in oral narratives and New Journalism reporting, as in (6a). It is also widely used to describe fictional eventualities whose temporal location relative to the utterance time is less obvious, as in (6b).

a. Inez, the maid, brings in lunch on a tray, one rare hamburger, one cheeseburger and a glass of tomato juice. Jane tastes the tomato juice. "Oh,__!" she says. "It's diet."

(Tom Wolfe, "The Girl of the Year")

b. Mr. Tulkinghorn takes out his papers, asks permission to place them on a golden talisman of a table at my Lady's elbow, puts on his spectacles, and begins to read by the light of a shaded lamp.

(Dickens, Bleak House)

Altshuler \& Schwarzschild (2014) propose that some embedded presents may be instances of the HP. We argue, however, that extant accounts of the HP (Schlenker 2004; Anand \& Toosarvandani 2017), designed for unembedded cases like (6a-b), do not easily extend to embedded environments. In particular, we show that embedded presents are available in free indirect discourse, a fact that we use to argue that embedded presents cannot be handled by temporal de re.

Instead, we propose to link the temporal shifting of the HP to the presence of an intensional operator NAR, a basic version of which is defined in (7). In essence, NAR is a temporally-aware version of Lewis's (1978) modal operator for fiction: it considers the worlds compatible with a salient story that is retrieved anaphorically (represented by the $n$ subscript).

$$
\begin{aligned}
& \llbracket \mathrm{NAR}_{n}-t_{i}-w_{j} \lambda w \phi \rrbracket^{u, a, g}=1 \text { iff } \\
& \forall\left\langle w^{\prime}, t^{\prime}\right\rangle \text { such that } w^{\prime} \text { is a world compatible with } g(n) \text { in } w_{j} \text { at } t_{i} \text { and } \\
& t^{\prime} \text { is the temporal vantage point on } g(n) \text { in } w_{j} \text { at } t_{i}, \\
& \llbracket \lambda w \phi \rrbracket^{u, a\left[\mathrm{TIME} \rightarrow t^{\prime}\right], g}\left(w^{\prime}\right)=1
\end{aligned}
$$

Unlike Lewis' operator, we propose that NAR considers times that represent the temporal vantage point on a story - the perspective from which the story is being considered - and it shifts the indexical time $\operatorname{TIME}(a)$ to that vantage point.

Importantly, the HP is used in both fiction and non-fiction narratives, with no significant linguistic differences across these contexts. If a NAR operator like (7) is responsible for the temporal shift of the HP, it should do this in an equivalent fashion whether the narrative is intended to be true or not. Although Lewis was concerned with how contingent facts about the actual world can intrude into our 
understanding of a fictional narrative, the ordering semantics he incorporates into his fictional operator comes in handy here. Building on his original work, as well as an extensive literature arising from it, we revise the NAR operator to naturally encompass both fictional and non-fictional narratives, while independently enforcing a temporal shift.

The paper is arranged as follows: In Section 2, we provide evidence that our instances of embedded present are the HP, based on a shared restriction on aksionsart and requirement for a narrative anchor. We then turn, in Section 3, to a potential analysis in terms of temporal de re, ruling it out by looking at free indirect discourse. In Section 4, we present our proposal for a NAR operator, focusing initially just on the temporal dimension. In Section 5, we consider the intensional dimensions of the operator.

\section{Three hallmarks of the historical present}

The HP has been characterized in terms of three hallmarks, two grammatical and one pragmatic (Anand \& Toosarvandani 2017). All three are found with our embedded presents.

Considering its grammatical properties first, the HP discusses a time interval that does not overlap the utterance time. While it is often used historically, so that it locates an eventuality anterior to the utterance time, as in (6a), it is also possible in the right circumstances to use the HP to talk about the future as well (Pancheva \& Zubizarreta 2020). Furthermore, while the canonical present is reserved for stative eventualities (whether lexical or derived, as with progressives or habituals), the HP is compatible with eventives as well: consider, for instance, the bolded verbs in (6). The embedded presents in $(5 \mathrm{a}-\mathrm{b})$ show both of these properties. The embedded eventualities occur prior to the utterance time (indeed, prior to the attitude time), and are eventive predicates - how long it takes him and that she leaves work to raise her family. This latitude in aksionsart is particularly surprising, given that embedded presents must be stative in the orthodox view (as must non-backshifted past tenses) (Ogihara 1996; Gennari 2003). If these are embedded HPs, however, the grammaticality of these eventive predicates is expected.

Beyond these grammatical distinctions, the HP has also been described as a pragmatic choice that results in a more vivid or transporting experience for the reader (Palmer 1965: 39, Leech 1971: 6-7, Close 1981: 106), an impression likely responsible for the HP being eschewed in journalism prior to New Journalism's emphasis on intersubjectivity and audience enjoyment. At the same time, more contemporary examinations of the HP within discourse analysis have downplayed the significance of this felt vividness, which they take to be an optional effect. The suggested core functions of the HP, in these approaches, include to segment a narrative by switching 
Embedded presents and the structure of narratives

in and out of the present tense (Wolfson 1979), to foreground particular episodes in the narrative (Fleischman 1990), or to mark the author/narrator's opinions within the text (internal evaluation, in Labov \& Waletzky's (1966) sense; Schiffrin 1981).

In all these characterizations, the HP is used to describe or discuss a narrative, a story of some sort, regardless of what its ultimate function may be. Accordingly, we might expect the HP not to be felicitous in typical information-seeking exchanges, and indeed it is not. Consider the following exchange, modeled after an example by Kratzer (1998: 106): $:^{3}$
A: [Looking up at a church] Who built this church?
B: (In the 1630s,) Borromini \{\#builds, built\} this church.

While the simple past is impeccable here, the HP creates the feeling that B is starting a story, something not especially apt for answering an information-seeking question. We note in this regard that questions that can be answered by an extended narrative are considerably easier to respond to with the HP.
A: [Looking up at a church] What's the history of this church?
B: (In the 1630s,) the Trinitarians are looking for an architect. Borromini volunteers to design it for free and is commissioned to build it, cementing his fame.

Leaving such complexities aside, our embedded presents are likewise impossible in an information-seeking exchange.
A: What is Warren's position on her career?
B: She said that she $\{\# l$ leaves, left $\}$ work to raise her family that year.

A crucial difference between this information-seeking context and the one above involves the hearer (and speaker)'s expectations: when the historical present is felicitous, it seems reasonable to assume, intuitively, that a story is being told. And adding In a 2007 interview to (10) makes B's reply better. In other words, our cases of embedded presents, just like the HP in root contexts, require what we can call a narrative anchor, which we will cache out below as anaphora to a salient narrative.

Before turning to a formal analysis, we should distinguish our cases of, what we believe to be embedded HPs from some superficially similar cases that have been mentioned in the literature. First, Altshuler \& Schwarzschild (2014) and Bary \& Altshuler (2015) discuss some cases of present-under-past which appear not to have

3 We note here that the HP feels off even if it is anchored by a temporal frame adverbial like in the 1630s. This is different from what Kratzer notes for the German Präteritum, though we leave detailed examination of this "narrative" past tense to future research. 
a double access reading: that is, the embedded eventuality intuitively fails to hold at either utterance time or attitude time. In (11), the embedded eventuality holds at the utterance time alone: the baggage claim agent cannot have the bicycle at the attitude time because it is on the flight at that point. Conversely, in (12), the eventuality holds at the attitude time alone: the eventuality of being in the room most likely fails to hold at the time of utterance.

(11) [To a baggage claim agent after arriving on a flight] On the flight, the flight attendant told me that you have my bicycle because it's oversized. (adapted from Altshuler \& Schwarzschild 2014: 47)

(12) Everyone was looking at us funny. I couldn't understand it. Then Paula came up to us, with horror in her eyes. She whispered in my ear that we're in a room full of anti-communists and my wife's coat is bright red.

(Bary \& Altshuler 2015: 104)

Somewhat differently, Klecha (2016) argues that hope admits present-under-present examples where the embedded eventuality occurs after the utterance time, as in (13).

Considering our diagnostics for the HP above, (12) and (13) fail to overlap the utterance time, while only (13) is eventive. As for aktionsart, replacing the stative predicates in (11) and (12) with eventive predicates, such pick up my bicycle or enter a room, leads to ungrammaticality, unless the predicates are interpreted habitually (in which case they are double access). Finally, only (12) seems to make reference to a story, but here we note an important difference from the examples in (4) and (5b). In our cases, the embedded eventuality is part of the narrative, whereas the embedding attitude is not (in both cases, that predicate serves to report a telling of the narrative). In (12), by contrast, the whispering is arguably part of the story. In that light, we note that converting (12) into the HP fails to license an eventive predicate under whisper.

(14) Then Paula comes up to us, with horror in her eyes. She whispers in my ear that \{we're in, \#we enter $\}$ a room full of anti-communists and my wife's coat is bright red.

This suggests to us that, whatever the ultimate account of the cases in (11-13) is, it is distinct from the cases we have been considering, where an embedded present picks out a time anterior to the utterance and attitude time. For these reasons, we will assume, for the remainder of the paper, that they have a separate explanation. ${ }^{4}$

4 For instance, the cases in (11) and (13) have been advanced as arguments against the Upper Limit Constraint (ULC; Abusch 1997), which prohibits embedded tenses from following the embedding attitude time (or its de nunc equivalent). If such critiques are accurate, the ULC will need revision. As an alternative, it seems to us also possible that the present in (11) is generic or futurate. 
Embedded presents and the structure of narratives

\section{Free indirect discourse}

Our cases of embedded present tense, then, look a great deal like the HP in unembedded contexts: they are temporally disconnected from the utterance time, they can be eventive, and they require a narrative anchor. Before moving on, though, one additional comparator is salient. Free indirect discourse (FID) is a narrative style that also interacts with indexicals. Its central temporal signature is that it shifts temporal adverbials like today, but not tense (Banfield 1982; Doron 1991).

She seated herself in silence again, rather sorry he had come to disturb her. Today she did not want him. (D. H. Lawrence, The First Lady Chatterley)

By contrast, while the HP (embedded or unembedded) allows temporal adverbials to shift, such a shift is optional (pace Schlenker (2004)). In (16), for example, it is possible for yesterday to refer to the day before the time of utterance, while today still shifts to the day of the eventuality described with the HP.

A pipe bursts under my sink yesterday morning while I'm eating breakfast and I'm panicking because I have a huge project deadline today.

Such mixed shifting is not attested for FID (though see Recanati 2000 for discussion of "intrusive" FID).

Beyond this, FID seems to prohibit de re across the board, including de re uses of names and definite descriptions (Doron 1991; Sharvit 2008). ${ }^{5}$ For example, given Luke's knowledge about his parentage in Star Wars: A New Hope, it is not appropriate to report his guess about what has happened to Obi-Wan at the close of the movie using any description other than Vader.

\{Vader, \#His father, \#Anakin\} was fighting his master, Luke guessed.

Similarly, pronouns coreferent with the attitude holder must be read de se (Sharvit 2008: 370). Thus, for example, if Luke mistook a picture of himself grinning for one of a young Leia, the use of masculine he is infelicitous, since Luke lacks the appropriate de se thought.

(18) [Luke looks at a picture of himself as a child, mistaking it for one of Leia] \{She, \#He\} was so happy then! Luke thought.

5 For the purposes of simplicity, we will assume in what follows that we are in the world of Star Wars, where there are many instances of double vision. Until now we have confined our attention to non-fictional narratives and similar examples can be constructed using historical instances, e.g., George Eliot/Mary Ann Evans, though elaborating the contexts would require a great deal of space. 
Such restrictions do not hold for the HP, embedded or otherwise. For example, in The Phantom Menace, Queen Amidala's first meeting with Chancellor Palpatine/Darth Sidious might be described as in (19). Similarly, the scene in (18) is fine in the HP without FID, as shown in (20).

(20) Luke glances at a picture of himself as a child, mistaking it for one of Leia. He thinks \{she, he $\}$ must be so happy in the picture.

If embedded HPs were instances of something like FID, they would have to be able to overcome FID's allergy to de re interpretation of entities and temporal expressions.

To hammer this point home, it is worth noting that it is possible to have embedded presents inside FID (i.e., situations where the main text tense is past), as long as there is a sufficient narrative anchor, as in (21) which builds off of (19) above.

Was someone working against her? Amidala wondered. She thought back to the events leading up to the attack. When she meets him after fleeing from Naboo, $\{$ Palpatine, \#Darth Sidious $\}$ is so solicitous. And then, on the Senate floor yesterday evening, he speaks glowingly about the Jedi, Amidala reminded herself. But, this morning he is cold to her, so cold.

Importantly, FID here blocks a de re reading of the name Darth Sidious, unlike in the "pure" HP use in (19). It thus appears that, while embedded presents are compatible with FID, they cannot be reduced to it, given their differing properties with respect to de re. Looking forward to the discussion in Section 4, the availability of presents in FID, as in (21), will suggest that embedded presents are also unlikely to be a species of de re temporal interpretation, given FID's general prohibition on de re.

\section{The proposal}

We propose that the HP is the product of a silent intensional operator, NAR, akin to Lewis's (1978) fiction operator. In Section 5, we will take a closer look at Lewis' operator, considering how its intensionality allows the same operator to account for the HP both in fictional and non-fictional narratives. For now, though, we concentrate on tense and the temporal components of NAR.

NAR shifts the relevant temporal perspective for tense to a temporal vantage point on a salient narrative. Building on existing bicontextual semantics (Schlenker 2004; Sharvit 2008; Anand \& Toosarvandani 2017), we take both present and past tense to be indexical to the time coordinate of a context of assessment (a), in MacFarlane's 
(2003) terms; this is formally distinct from the context of utterance $(u)$ that encodes contextual information about the speech situation.

$$
\begin{aligned}
& \text { a. } \llbracket \operatorname{PRES}_{i} \rrbracket^{u, a, g}=g(i) \text {; defined iff } g(i) \subseteq \operatorname{TIME}(a) \\
& \text { b. } \llbracket \operatorname{PAST}_{i} \rrbracket^{u, a, g}=g(i) \text {; defined iff } g(i)<\operatorname{TIME}(a)
\end{aligned}
$$

To account for the HP in root contexts, it would sufficient if the pragmatics of speech permitted an utterance to be interpreted relative to a context of assessment distinct from the context of utterance (Schlenker 2004; Anand \& Toosarvandani 2017). Then, $\operatorname{TIME}(a)$ could be an interval distinct from TIME $(u)$ wide enough to contain non-stative eventualities, thereby by capturing the grammatical hallmarks of the HP.

But if the choice of $\operatorname{TiME}(a)$ is reserved solely for the utterance, there would be no way to capture embedded presents: changing $\operatorname{TIME}(a)$ for the entire utterance will not capture the fact that, in (4), the embedding predicate is canonically interpreted before lawyer's speech act, but after the time of Clark's traffic incident. Thus, some way of shifting $\operatorname{TIME}(a)$ is needed in embedded environments. This is what the NAR operator accomplishes. It is a temporal perspective shifting version of, roughly, in that story, so that our examples of embedded presents can be paraphrased informally along the following lines:

a. And you said, in your account of the traffic incident, you are moving 15 miles an hour.

b. I can't remember how long, in the account of this trip, it takes him.

$$
=(5 \mathrm{a})
$$

c. In a 2007 interview, she said that, in her autobiographical narrative, she leaves work to raise her family that year.

This is, admittedly, a somewhat complicated bundle of operations, and so before we present a more formal account of the NAR operator, it is useful to first eliminate some less elaborate alternatives.

\subsection{Two possible approaches}

There are two other, intuitively reasonable ways of dealing with the issue of embedded presents, though both face empirical challenges.

The first would be to analyze these embedded tenses as bound, building on the semantics of sequence of tense. All theories of sequence of tense allow for such "null" tenses, illustrated in the LF in (24b). The lexical semantics of the attitude predicate identifies this bound time with the de nunc time of the attitude, which can account for "simultaneous" readings of past-under-past sentences. 
a. Warren said that she lived in Boston.

b. PAST $_{4}$ Warren say- $w_{0} \lambda_{13} \lambda_{7} \lambda_{2} t_{7}$ she ${ }_{13}$ live- $w_{2}$ in Boston

How bound tenses receive the pronunciation they do is the subject of theoretical debate (see Ogihara \& Sharvit 2012). But they can only be realized in this way in the presence of a "trigger," a superordinate tense with the same morphological tense (or a congruent attitudinal nominal, e.g., Warren's statement that...).

In the case of our embedded presents in (4-5), the matrix attitude predicate cannot serve as a suitable morphological trigger - it is invariably in the past tense - and, furthermore, the embedded eventuality precedes the de nunc time. One could imagine a silent, but morphologically active, operator $\mathrm{OP}_{v}$ that would bind a tense and set it to an anaphorically retrieved time interval $(v)$.

$$
\llbracket \mathrm{OP}_{\boldsymbol{v}} \lambda t \phi \rrbracket^{u, a}=1 \text { iff } \llbracket \lambda t \phi \rrbracket^{u, a}(\mathrm{v})=1
$$

This would intervene between the attitude predicate and the embedded clause, serving as the relevant morphological trigger for the embedded bound tense:

a. Warren said that she leaves work.

b. $\mathrm{PAST}_{4}$ Warren say- $w_{0} \lambda_{13} \lambda_{7} \lambda_{2} \mathrm{OP}_{v} \lambda_{8} t_{8}$ she 13 leave- $w_{2}$ work

In this approach, not only does the morphological presence of $\mathrm{OP}_{v}$ lack motivation, but it also fails to capture that it is not just the present tense that shifts in HP contexts. All tenses can shift, including past tenses, as in (27a-b).

a. Warren says that she is fired after she announced her pregnancy.

b. Clark said that he (had) nearly collided before, and so he gingerly approaches the intersection.

The announcing and colliding in $(27 \mathrm{a}-\mathrm{b})$ are anterior to some salient time containing the firing and approach, respectively. Thus, our cases of embedded presents cannot simply involve the binding of a tense: it is a general evaluation point for tense that is shifted. $^{6}$

A different approach is suggested by Altshuler \& Schwarzschild (2014). They take the embedded present in (11) to be a de re tense, raising the possibility that our cases might be de re HPs. To make this concrete, we can assume that temporal de re is an instance of res-movement (Heim 1994), where the attitude predicate say $y_{\rho}$ takes the de re interval and a temporally-centered proposition $p$ as arguments.

6 It would be possible in principle to place $\mathrm{OP}_{v}$ so it does not scope over the past tense clauses in (27), but this fact about past tense is quite general. Ultimately, it will have to scope solely over the present tense. 
Embedded presents and the structure of narratives

$$
\begin{gathered}
\llbracket \text { say }_{\rho} \rrbracket^{u, a}=\lambda t \lambda p \lambda x .1 \text { iff } \forall\left\langle x^{\prime}, t^{\prime}, w^{\prime}\right\rangle \text { compatible with } \\
\quad S P E E C H_{x, w, t}\left[p\left(x^{\prime}\right)\left(\rho\left(x^{\prime}\right)\left(t^{\prime}\right)\left(w^{\prime}\right)\right)\left(w^{\prime}\right)=1\right]
\end{gathered}
$$

According to (28), $s a y_{\rho}$ does not evaluate $p$ with respect to the de nunc time $t^{\prime}$, but the counterpart of the res-moved tense under the de re acquaintance relation $\rho$. The LF for (26) is the following under this approach: ${ }^{7}$

$$
\mathrm{PAST}_{4} \text { Warren say- } w_{0}\left[\mathrm{OP}_{\mu} \mathrm{PRES}_{16}\right] \lambda_{13} \lambda_{7} \lambda_{2} t_{7} \text { she } 13 \text { leave- } w_{2} \text { work }
$$

This proposal relies on a temporal shifting operator for the historical present, $\mathrm{OP}_{\mu}$, which sets $\operatorname{TIME}(a)$ to a salient interval $\mu$, as in the bicontextual theories of the HP we discussed above.

$$
\llbracket \mathrm{OP}_{\mu} \alpha \rrbracket^{u, a}=\llbracket \alpha \rrbracket^{u, a[\operatorname{TIME} \rightarrow \mu]}
$$

Since the HP is achieved by an operator, it can apply narrowly to the res, thereby not affecting the matrix canonical past. As it stands, the embedded past tenses in (27) will not be shifted. However, this is a result of technical simplifications: in an LF that allows multiple res terms, one could move multiple tenses with $\mathrm{OP}_{\mu}$ on top of all of them. This is an important improvement over the binding analysis: since past and present are both sensitive to the same temporal evaluation point, shifting this one point affects both tenses at once.

Despite these benefits, we do not believe that this account can work because of an empirical problem that we introduced in Section 3. Embedded presents are licensed in FID, even though FID blocks de re interpretation, including for temporal adverbials and for present tense in double access uses. While we cannot rule out that there is a special proviso on that ban (as, indeed, seems to hold for personal pronouns; Sharvit 2008), it seems deeply stipulative.

In addition, while we have concentrated on the HP in non-fictional narratives, we note that the same puzzles exist for the HP in fictional narratives. A fictional narrative can be told or reported with past or present tense, in both embedded and unembedded environments:

$$
\text { (Grace thought that) \{Anakin, Vader }\} \text { lost, loses }\} \text { his pod race. }
$$

In this way, fictional narratives are linguistically exactly like non-fictional narratives. Now, it may be that the embedded present in (31) arises for a different reason than the one in (5b), but under the de re theory we have been considering, it must be for a different reason: there is often no particular salient interval we are considering.

7 Here, the acquaintance relation is a centered individual concept, perhaps something of the form $\lambda x \lambda t \lambda w$. the unique $t^{\prime \prime}$ such that $t^{\prime \prime}$ is the the final day of $x$ 's first trimester in $w$ at $t$, and we suppress the condition of acquaintance, namely that $\rho$ (Warren $)(g(4)(g(0))=g(16)$. 
Indeed, as stories stray further from our world, the constraints on when they take place become so vague that we often do not even ponder them. Put this way, the problem in (31) is not why the embedded present is licensed, but rather, why any tense is licensed.

\subsection{The narrative operator (a first pass)}

Taking stock, we have argued for four points. First, there exist embedded instances of the HP, which are a prima facie challenge for utterance-level pragmatic accounts of the HP. Second, all instances of the HP, whether embedded or not, involve a narrative anchor. Third, a profitable way of thinking about the HP is as shifting an indexical coordinate (as opposed to binding). Finally, whatever is responsible for the shift should be possible under FID (and hence cannot be attributed to de re interpretation mechanisms).

As we prefigured earlier, our approach builds on Lewis's (1978) fictional operator, an intensional operator that, as a first approximation, quantifies over worlds compatible with a story. It is this link to a story that serves to capture the narrative anchor requirement. We incorporate the temporal shifting of $\mathrm{OP}_{\mu}$ in (30) into this operator, identifying the interval $\mu$ with the timeline of the story. A first version of NAR is given below:

$$
\begin{aligned}
& \llbracket \mathrm{NAR}_{n}-t_{i}-w_{j} \lambda w \phi \rrbracket^{u, a, g}=1 \text { iff } \\
& \forall w^{\prime} \text { such that } w^{\prime} \text { is a world compatible with } g(n) \text { in } w_{j} \text { at } t_{i}, \\
& \text { for the smallest interval } t^{\prime} \text { containing the events of } g(n) \text { in } w_{j} \text { at } t_{i}, \\
& \llbracket \lambda w \phi \rrbracket^{u, a\left[\operatorname{TIME} \rightarrow t^{\prime}\right], g}\left(w^{\prime}\right)=1
\end{aligned}
$$

A narrative is modeled here as a conversational background (abstracting away from how a narrative conversational background needs to be organized). The NAR operator is anaphoric to some salient narrative $g(n)$ in the context, quantifying over those worlds compatible with the propositions in the conversational background evaluated at the local world $w_{j}$ and time $t_{j}$. This sensitivity to local evaluation allows, for example, for Warren's version of her narrative to vary from statement to statement, while still allowing those accounts to be about the same thing, Warren's history.

The semantics in (32) shifts $\operatorname{TIME}(a)$ to the timeline of the narrative, thereby enabling the HP. Given this, an LF and semantics for (27) can be sketched as follows:

$$
\begin{aligned}
& \text { a. PAST } 4 \text { Warren say- } w_{0} \lambda_{13} \lambda_{7} \lambda_{2} \mathrm{NAR}_{9}-t_{7}-w_{2} \lambda_{5} \text { PRES }_{16} \text { she } 13 \text { leave- } w_{5} \\
& \text { work } \\
& \text { b. } \forall\langle w, t, x\rangle \in \operatorname{SPEECH} H_{\text {Warren, } g(4), g(0)} \forall w^{\prime} \text { compatible with } g(9) \text { in } w \\
& \quad \text { at } t \exists e\left[\text { leave }\left(e, x, w^{\prime}\right) \& \tau(e) \subseteq g(16)\right] \text {; } \\
& \quad \text { defined iff } g(16) \subseteq \text { the smallest interval containing the events } \\
& \quad \text { of } g(n) \text { and } g(4)<\operatorname{TIME}(u)
\end{aligned}
$$


The same logic holds for presents embedded below an FID operator like that of Sharvit (2008): the world and time indices of NAR will instead be bound by the FID operator. Since $t^{\prime}$ is determined by the story timeline within the attitudinal world of evaluation, we do not encounter the problems for the de re HP theory.

While we have illustrated this for a non-fictional narrative, note that this semantics also captures uses of the HP in fiction, like (31), since $t^{\prime}$ would be set to, for example, the interval for The Phantom Menace. It does not, however, deal with past tense in fictional narratives, one of the goals we set for ourselves, and so we must elaborate on the semantics for NAR in (32). In order to do this, we have to determine what the difference between the past and present in (31) amounts to. Intuitively, this seems to be a difference in temporal viewpoint — with the HP, the events of the narrative transpire simultaneous with a temporal perspective, $\operatorname{TimE}(a)$, while with the past, the narrative view is backwards looking. That is, the difference amounts to a choice in vantage point on the narrative. Although a narrative conversational background contains a series of thematically coherent eventualities, it does not provide an intrinsic temporal perspective on those eventualities, leaving that perspective a choice of the telling.

In this light, we propose to make the temporal vantage point a component of the semantics of NAR:

$$
\begin{aligned}
& \llbracket \mathrm{NAR}_{n}-t_{i}-w_{j} \lambda w \phi \rrbracket^{u, a, g}=1 \text { iff } \\
& \forall\left\langle w^{\prime}, t^{\prime}\right\rangle \text { such that } w^{\prime} \text { is a world compatible with } g(n) \text { in } w_{j} \text { at } t_{i} \text { and } \\
& t^{\prime} \text { is the temporal vantage point on } g(n) \text { in } w_{j} \text { at } t_{i}, \\
& \llbracket \lambda w \phi \rrbracket^{u, a\left[\mathrm{TIME} \rightarrow t^{\prime}\right], g}\left(w^{\prime}\right)=1
\end{aligned}
$$

The tenses used in a narrative thus reflect the relation between temporal vantage point and the timeline of the narrative. Many canonical tellings (fictional or not) involve a vantage point posterior to the events of the story, leading to a narrative past, while the HP, as we have seen, results from a vantage point of the entire story timeline. In principle, we might expect any number of additional relations, but some are much rarer than others. For example, the temporal vantage point could precede the narrative timeline, though to our knowledge this is a vanishingly rare choice, reserved for famously experimental works like Brooke-Rose's (1984) Amalgamemnon. The vantage point could also be set to a time inside the timeline, so that some events are in the past, others in the present, and still others in the future. This style is actually quite common in non-fictional narrative features, using the events of the hook of the feature as vantage point. As for fiction, Kelsey Sasaki (p.c.) pointed us to the Chiang (1998) novella "The story of your life" (the basis for the movie Arrival), which is told entirely from the vantage point of the moment before a (foreseen) conversation that introduces the novella, not unlike the function of the hook in non-fictional features. Thus, it appears that vantage points are remarkably 
flexible, though we leave the task sorting out why some forms are uncommon to future work.

\section{Considering intensionality}

One of the signatures of our account is a linking of the possibility of temporal shifting to intensionality. While it is reasonable to suggest that works of fiction (and thus discussions about those works) invokes some form of intensionality, it is less clear that instances of non-fiction should as well. We might even wonder whether they should be assimilated to the fictional cases at all, as arising from the same NAR operator.

Evidence for an additional layer of modality even in non-fictional cases comes from examples in the HP like (35-36), where a proposition that must hold in the narrative is not veridical relative to the local evaluation world.

Sean went to the Oval Office to get the story straight about the Trump Tower meeting. He thought that (in the White's House account,) Don Jr. and Kushner go to talk about Russian adoptions. But he wanted to make sure.

Ruth only paid cursory attention to the news coverage of the birther movement in 2008. She couldn't remember whether (in the birther narrative,) Obama is born in Kenya or in Nigeria. But she did know that he is born in Africa.

Sean Spicer, surely, does not really believe that the two brothers-in-law went to Trump Tower to talk about Russian adoptions (rather: he knows they went to discuss Putin's request to lift sanctions on Russian nationals). Nor does Ruth really believe the birther lie that Obama is not a natural-born citizen. Here, the issue is what each of them thinks the content of some salient narrative is, and the proposed operator in (34) predicts these readings. This is because NAR is rather silent on the intent and on the success of a narrative. It does not comment on whether the narrative $g(n)$ is true, be it relative to the local world $w_{j}$ or matrix world $w_{0}$, and more generally, it does not encode any notion of the world that a story is about. ${ }^{8}$

But the intensional component of the NAR operator, in its current form, is too simplistic for reasons Lewis (1978: 39) discusses, and it is important to determine whether Lewis' worries prevent us from pursuing a unified semantics for fictional

8 Introducing an explicit notion of the world that a story is about may seem relatively harmless for nonfiction, but it is significantly more fraught for fiction. Stories never provide a complete description of any world, and so it is not clear what world a fictional narrative would be about. Such a move would also risk getting tangled up in the perilous question of whether there are such things as fictional worlds (see, for instance, Walton 1990: 55-77 for discussion). 
and non-fictional narratives. One of his main concerns was accounting for how understanding of fiction happens against a background of contingent facts about the actual world. ${ }^{9}$ In Lewis' paradigm example, we understand that Sherlock Holmes' flat on Baker Street is closer to Paddington Station than Waterloo Station, even though a map of London is not part of the story. Quantifying over all worlds compatible with just the propositions in the story, as NAR in (34) does, would incorrectly admit worlds in which his lodgings are closer to Waterloo. Intuitively, such worlds are excluded due to facts about London in the actual world, but precisely how that intuition should be cached out has been the subject of substantial inquiry since Lewis' original work (Walton 1990; Woltserstorff 1980; Currie 1990; Phillips 1999; Woodward 2011; Friend 2017). Here, we will review the distinctions drawn

and, without trying to resolve any issues, content ourselves with asking how they might affect our project of folding non-fictional narratives in with fictional ones.

\subsection{Reality in stories}

When hearing or reading a story, we automatically fill in innumerable details. In the world of The Adventures of Sherlock Holmes, we understand London to have the same geography as in our own world, but we do not understand, as Lewis points out, Holmes to have a third nostril or to have visited Saturn. This type of reasoning, he argues, is like counterfactual reasoning. Thus, Lewis proposes that the prejacent is evaluated at worlds that are not only compatible with the story, but also are the best such worlds based on some metric. He considers two possible orderings for fictional narratives. Given the discussion above, one reasonable ordering involves similarity to the actual world, much as in orthodox accounts of counterfactual conditionals. Setting aside the necessary temporal component that we were concerned earlier, Lewis' operator can be stated in Kratzerian terms, as in (37), with an ordering source $(f)$ that is totally realistic: $\left\{p: p\right.$ is true in $\left.w_{j}\right\} .{ }^{10}$

$$
\begin{aligned}
& \llbracket \mathrm{NAR}_{n}-w_{j} \lambda w \phi \rrbracket^{u, a, g}=1 \text { iff } \\
& \forall w^{\prime} \in \max _{f\left(w_{j}\right)}\left(\left\{w^{\prime}: w^{\prime} \text { is compatible with } g(n) \text { in } w_{j} \text { at } t_{i}\right\}\right), \\
& \llbracket \lambda w \phi \rrbracket^{u, a, g}\left(w^{\prime}\right)=1
\end{aligned}
$$

As Lewis and many others have pointed out, however, requiring a totally realistic ordering renders fiction too similar to counterfactuals, too dependent on the actual

9 Lewis' other main concern is that it is not just stories themselves that seem relevant for determining truth in fiction, but also their tellings, which contribute situational context and paralinguistic or vocal features to render each telling unique. This is missing from our account currently.

10 In our discussion here, we set aside entirely the problem of impossible fictions, or stories with contradictory contents. Lewis addresses this issue in his original article, as well as in the postscripts in Lewis 1983. 
world. For example, many details simply go unmentioned in fiction, and so a totally realistic ordering would make it true in our world to say (38). ${ }^{11}$

(In The Adventures of Sherlock Holmes,) Trump wins the 2016 election.

A similar problem arises when authorial privilege (an arguably constitutive property of fiction) conflicts with what is true in $w_{j}$. For example, in The Adventure of the Speckled Band, Holmes concludes that a murder was effected via an adder which climbs up a bell rope to reach the victim, despite the actual world fact that the species of adder in question cannot climb. With a totally realistic ordering source, it would be true to say (39), contrary to Holmes' putative infallibility, and, more importantly, Conan Doyle's prerogatives as author (no matter whether he is mistaken about the nature of the actual world).

(In The Adventure of the Speckled Band,) Holmes makes a mistake.

At the same time, Lewis cautions from investing too much in the beliefs of the author - or the audience - alone: if Conan Doyle believed in purple gnomes, their existence would not as a consequence become part of the world of Sherlock Holmes (nor would it if a member of the audience did). Instead, Lewis' proposal aims to strike a middle-course, making truth in a fiction dependent on the "collective beliefs of the community of origin" of the story. Concretely, $f$ in (37) would then be: $\{p: p$ is a collective belief of the community of origin of $g(n)$ in $\left.w_{j}\right\}$. For the cases we have considered so far, this seems to make the right cut, given common beliefs about locations in London, the prevalence of third nostrils, or the possibility of traveling to Saturn.

But Lewis' seemingly reasonable approach runs into its own problems, as much subsequent investigation has uncovered. As Walton observes, ordering sources grounded in collective beliefs still require restriction to story-relevant propositions - (In the Adventures of Sherlock Holmes, ) God exists does not seem to be true, even though Victorians were collectively theists. And, of course, this kind of ordering threatens to turn comprehension of a work of fiction into an originalist project Friend (2017), so that verifying a claim like In Wolf Hall,... would require knowing what people today believe about the Tudor era.

The most important point, however, seems to be that, even granting a role to collective beliefs in determining the story worlds, there clearly seem to be other factors. Lewis himself acknowledges that something more is needed to allow for what he calls intra- and interfictional carryover: genre conventions or other fictional

11 The solution to this problem may lie in simply restricting the ordering source to those facts that are relevant for the story (Walton 1990: 149-150), though then the question becomes how to decide which propositions are the ones that belong in the background of the story. 
conventions, which exceed any specific fictional work (for instance, the appropriate gait for a zombie or where leprechauns hide gold; arguably, Holmes' infallibility is another example). And, Walton points (p. 162) to the suicide of Mrs. Verloc in the Secret Agent, which is described solely through a newspaper headline: "Suicide of lady passenger from a cross-channel boat." The collective beliefs of the community of origin are completely unhelpful for ensuring that the claim (In the Secret Agent,) Mrs. Verloc committed suicide is true; rather, what is needed are beliefs about how authors tend to signal important events indirectly in narrative works.

The above considerations lead to the conclusion that there is no simple, universal ordering source for the NAR operator, at least as far as fiction is concerned. Indeed, such a conclusion feels appropriate for fictional narratives, which are, informally speaking, about a "story world" that is by its very nature underdetermined.

\subsection{Accounting for non-fiction}

In sharp contrast to the complexities of fiction, non-fictional narratives are quite simple. They are about the actual world, which is not under-determined; the method for ascertaining the truth of a non-fictional narrative consists entirely of inspecting the actual world. Thus, while Lewis' attention was drawn entirely to fiction, his operator can be extended to narratives about the actual world by taking the ordering source for these to necessarily be totally realistic. Thus, we revise our proposal for the NAR operator as follows, integrating the temporal component with a counterfactional semantics, as Lewis proposes:

$$
\begin{aligned}
& \llbracket \mathrm{NAR}_{n}-w_{j} \lambda w \phi \rrbracket^{u, a, g}=1 \text { iff } \\
& \forall\left\langle w^{\prime}, t^{\prime}\right\rangle \text { such that } w^{\prime} \in \max _{f\left(w_{j}\right)}\left(\left\{w^{\prime}: w^{\prime} \text { is compatible with } g(n)\right.\right. \\
& \text { in } \left.\left.w_{j} \text { at } t_{i}\right\}\right) \text { and } t^{\prime} \text { is the temporal vantage point on } g(n) \text { in } w_{j} \text { at } t_{i}, \\
& \llbracket \lambda w \phi \rrbracket^{u, a\left[\operatorname{TIME} \rightarrow t^{\prime}\right], g}\left(w^{\prime}\right)=1 \text {, where } f \text { is: } \\
& \text { (i) totally realistic, i.e., }\left\{p: p \text { is true in } w_{j}\right\} \text {, or } \text { (non-fiction) } \\
& \text { (ii) a product of the collective beliefs of the community of origin } \\
& \text { of } g(n) \text { and any other relevant considerations }
\end{aligned}
$$

Like a modal, the ordering source for NAR varies by context. When it is anaphoric to a story that is intended to describe the actual world, the ordering source is totally realistic; when it is fictional, a different, more complex ordering is involved. It may even be that the ordering source for fiction is not constant, varying by context with what is important about the story to conversational participants.

When the ordering source is totally realistic, the intensionality of the NAR operator will not always be directly observable. Sometimes it is, as in the narratives we considered in (35-36), where the propositions in the story are not veridical relative to the attitude holder's doxastic state, even if they are about the actual world. 
But when a non-fictional narrative is veridical - when all propositions in $g(n)$ are true in $w_{j}$ - then NAR $\phi$ will be true in $w_{j}$ just in case $\phi$ is true in $w_{j}$. In this case, then, the intensionality will be felt solely through the need for a salient story in the context, for a narrative anchor. We saw this for the HP in root contexts, as in (8), and we see it also when the HP is embedded under an attitude verb. Omitting the prefix in the Senate report in (41) is only possible when a salient narrative is available.

Biden pointed to the Senate report on Burisma's activities in Ukraine. He reiterated that( in the Senate report,) Hunter does nothing wrong.

Our account, then, draws no essential difference between fiction and non-fiction stories, leaving that job to the contextual vagaries of ordering. This seems a desirable outcome, since we have found no linguistic correlates of the difference. For the same reason, our account also does not differentiate between stories that vary along the other dimensions we have considered (verdical vs. non-veridical and true in actual world vs. not).

\section{Conclusion}

We began this paper with a puzzle about non-utterance indexical embedded present tense, using it to argue for an intensional source for the historical present and for a more capacious version of Lewis' modal fictional operator, one that is compatible with non-fictional narratives. Our proposal gives rise to a host of questions. One set of questions relates to the distributional restrictions on NAR: Can it go in other places besides root and attitude-embedded environments? We believe it can, such as under epistemic modals (e.g., Warren finally exits after Super Tuesday. She must get a phone call from a trusted colleague.) and causal connectives like because, and we look forward to probing this possibility further. Another set of questions concerns the structure of narratives and how it interfaces with the temporal vantage point. Here, we have rendered narratives as conversational backgrounds, but stories arguably have a rich internal structure, not only the story-internal timeline of events (what narratologists call the fabula), but also the way a telling describes those events (the syuzhet). We suspect that the mereology of both fabulas and syuzhets is exploited by language users when setting temporal vantage points (otherwise, how could past tense be used to describe events previously described in a piece in the HP?). Moving forward on these points will undoubtedly require a more nuanced view of how times are conceived in narratives than the story we have begun here. 
Embedded presents and the structure of narratives

\section{References}

Abusch, Dorit. 1997. Sequence of tense and temporal de re. Linguistics and Philosophy 20. 1-50. doi:10.1023/A:1005331423820.

Altshuler, Daniel \& Roger Schwarzschild. 2014. Correlating cessation with double access. Amsterdam Colloquium 19. 43-50.

Anand, Pranav \& Maziar Toosarvandani. 2017. Unifying the canonical, historical, and play-by-play present. Sinn und Bedeutung 21. 19-34.

Banfield, Ann. 1982. Unspeakable Sentences: Narration and Representation in the Language of Fiction. Boston: Routledge and Kegan Paul.

Bary, Corien \& Daniel Altshuler. 2015. Double access. Sinn und Bedeutung 19. 89-106.

Brooke-Rose, C. 1984. Amalgamenon. London: Carcanet Press.

Chiang, Ted. 1998. Story of your life. In Patrick Nielsen Hayden (ed.), Starlight 2, 257-314. New York: Tor.

Close, R. A. 1981. English as a Foreign Language: Its Constant Grammatical Problems. London: George Allen and Unwin 3rd edn.

Currie, Gregory. 1990. The Nature of Fiction. Cambridge: Cambridge University Press.

Doron, Edit. 1991. Point of view as a factor of content. Semantics and Linguistic Theory (SALT) 1. 51-64. doi:10.3765/salt.v1i0.2997.

Fleischman, Suzanne. 1990. Tense and Narrativity: From Medieval Performance to Modern Fiction. Austin: Univeristy of Texas Press.

Friend, Stacie. 2017. The real foundation of fictional worlds. Australasian Journal of Philosophy 95(1). 29-42. doi:10.1080/00048402.2016.1149736.

Gennari, Sylvia. 2003. Tense meanings and temporal interpretation. Journal of Semantics 20. 35-71. doi:10.1093/jos/20.1.35.

Heim, Irene. 1994. Some comments on Abusch's theory of tense. In Ellipsis, Tense, and Questions, 143-170. Amsterdam: Department of Philosophy, University of Amsterdam.

Klecha, Peter. 2016. Modality and embedded temporal operators. Semantics and Pragmatics 9(9). 1-55. doi:10.3765/sp.9.9.

Kratzer, Angelika. 1998. More structural analogies between pronouns and tense. Semantics and Linguistic Theory (SALT) 8. 92-110. doi:10.3765/salt.v8i0.2808.

Labov, William \& Joshua Waletzky. 1966. Narrative analysis: Oral version of personal experience. In June Heim (ed.), Essays on the Verbal and Visual Arts, 12-44. Seattle: University of Washington Press.

Leech, Geoffrey N. 1971. Meaning and the English Verb. London: Longman.

Lewis, David. 1978. Truth in fiction. Anmerican Philosophical Quarterly 15(1). 37-46. 
Lewis, David. 1983. Truth in fiction. In Philosophical Papers, vol. 1, 261-280. Oxford: Oxford University Press.

MacFarlane, John. 2003. Future contingents and relative truth. The Philosophical Quarterly 53(212). 321-336.

Ogihara, Toshiyuki. 1996. Tense, Attitudes, and Scope. Dordrecht: Kluwer.

Ogihara, Toshiyuki \& Yael Sharvit. 2012. Embedded tenses. In Robert I. Binnick (ed.), The Oxford Handbook of Tense and Aspect, 638-668. Oxford: Oxford University Press.

Palmer, F. R. 1965. The English Verb. London: Longman 2nd edn.

Pancheva, Roumyana \& Maria Luisa Zubizarreta. 2020. Temporal reference in the absence of tense in Paraguayan Guaraní. North East Linguistic Society (NELS) 50.

Phillips, John F. 1999. Truth and inference in fiction. Philosophical Studies 94(3). 273-293. doi:10.1023/A:1004239709212.

Recanati, F. 2000. Oratio Obliqua, Oration Recta. Cambridge, MA: MIT Press.

Schiffrin, Deborah. 1981. Tense variation in narrative. Language 57(1). 45-62. doi:10.2307/414286.

Schlenker, Philippe. 2004. Context of thought and context of utterance (a note on free indirect discourse and the historical present). Mind and Language 19(3). 279-304.

Sharvit, Yael. 2008. The puzzle of free indirect discourse. Linguistics and Philosophy 31. 353-395.

Walton, K. 1990. Mimesis as Make-believe: On the Foundations of the Representational Arts. Cambridge, MA: Harvard University Press.

Wolfson, Nessa. 1979. The conversational historical present alternation. Language 55. 168-182. doi:10.2307/412521.

Woltserstorff, Nicholas. 1980. Worlds and Works of Art. Oxford: Clarendon Press.

Woodward, Richard. 2011. Truth in fiction. Philosophy Compass 6(3). 158-167. doi:10.1111/j.1747-9991.2010.00367.x.

Pranav Anand

Stevenson Academic Services

1156 High St.

Santa Cruz, CA 95064

panand@ucsc.edu
Maziar Toosarvandani

Stevenson Academic Services

1156 High St.

Santa Cruz, CA 95064

mtoosarv@ucsc.edu 